\title{
A cross-sectional and comparative study of impulsivity and personality profile in euthymic bipolar affective disorder patients and controls
}

\author{
K Sandhya ${ }^{1}$, S Sireesha ${ }^{2 *}$, Sudharani ${ }^{3}$ \\ ${ }^{\mathbf{1}}$ Assistant Professor, ${ }^{2}$ Professor, ${ }^{\mathbf{3}}$ Associate Professor, Dept. of Psychiatry, Institute of Mental Health (IMH), OMC, Hyderabad, Telangana, \\ India
}

*Corresponding Author: S Sireesha

Email: sireeshasvmc@gmail.com

\begin{abstract}
Introduction: Bipolar patients show increased impulsivity during symptomatic period. Impulsivity during euthymic phase is not much studied. Impulsivity is a risk factor for future episodes of BPAD, suicidality, poor functional outcome and mortality.

Aims and Objectives: The current study conducted during euthymic phase to study impulsivity compared with controls and to assess any particular personality trait manifests in the disorder. It is also aimed to study the correlation between the variables "impulsivity and personality" profiles among cases.

Materials and Methods: This study was conducted on patients of euthymic bipolar disorder $(n=50)$ and healthy controls ( $\mathrm{n}=50)$. Patients were assessed using Hamilton Depression Rating Scale (HDRS) and Young Mania Rating Scale (YMRS) to diagnose remission. They were administered Barratt Impulsiveness Scale-11(BIS-11) and Eysenck Personality Inventory (EPI).The healthy attendants of bipolar patients without any psychiatric disorder were taken as controls.

Results: All three facets of impulsivity of test and control sample were found to be statistically significant. The difference between test and control scores of extraversion was found to be statistically significant $(\mathrm{p}=.002)$. Among test sample the extraversion scale and total score of Barratt impulsivity scale and its subscale facets i.e., attentional, motor and non-planning showed positive correlation. Among test sample, correlation between extraversion, BIS total score $(\mathrm{p}=0.018)$ and non-planning impulsivity $(\mathrm{p}=0.026)$ was found significant. The neurotic scale also showed positive correlation with BIS total and sub scales but none of them found statistically significant among test sample.

Conclusions: Impulsivity was found to be increased during euthymic phase of bipolar patients. It is associated with substance abuse, suicide and poor functional outcome. Hence it is very important that impulsivity has to be assessed in all bipolar affective disorder patients.
\end{abstract}

Keywords: Bipolar disorder, Impulsivity, Euthymic.

\section{Introduction}

Bipolar affective disorder (BPAD) is a severe affective syndrome characterized by a cyclical pattern of mood changes (e.g. depression, mania/ hypomania and euthymia) and a high likelihood of comorbidity with other disorders (PAULO 2012). ${ }^{1}$ This disorder is characterized by repeated (i.e. at least two) episodes in which the patient's mood and activity levels are significantly disturbed, this disturbance consisting on some occasions of an elevation of mood and increased energy and activity (mania or hypomania), and on others of a lowering of mood and decreased energy and activity (depression). Characteristically, recovery is usually complete between episodes (ICD-1O). ${ }^{2}$ The World Health Organization (WHO) labelled BPAD as one of 10 major causes of disability (Mather's C2004). ${ }^{3}$ It is estimated to affect between $0.3 \%$ and $1.5 \%$ of individuals worldwide (Weissman MM1996). ${ }^{4}$ Bipolar spectrum disorders have been less extensively studied but are likely to be more prevalent, affecting up to $8 \%$ of the population (Angst 1998). ${ }^{5}$ This disorder has been associated with high rates of episode relapse and hospitalizations (Erin E Michalak $2005)^{6}$ financial and social impairments.

Impulsivity definition by Daruna and Barnes $(1993)^{7}$ who stated that impulsivity encompasses a range of actions which are poorly conceived, prematurely expressed, unduly risky or inappropriate to the situation and that often result in undesirable consequences'. Researchers agree that impulsivity was found to be multi-faceted (Barratt 1994; Reynolds et al. 2006), ${ }^{8,9}$ it had many relationships with bipolar disorder and depends on the way in which it was measured (F. Gerard Moeller 2001). ${ }^{10}$ Related to susceptibility: adolescents at risk for mania as more "impulsive" than their peers (Sunohara GA 1999). ${ }^{11}$ Related to episodes of illness or to prodromes of episodes: increased impulsivity may accompany episodes. Related to pathophysiology of illness: impulsivity could result from some combination of increased norepinephrine (Gray JA1995, ${ }^{12}$ CoccaroEF1989), ${ }^{13}$ decreased serotonin (Linnoila M1983), ${ }^{14}$ or impaired prefrontal cortex function (Jentsch JD. 1999). ${ }^{15}$ In bipolar disorder, impulsivity and depression, leads to an increased use of maladaptive coping strategies and impair functionality. Therefore, it seems appropriate in the treatment of bipolar disorder patients to focus on aims like impulse control in order to improve functionality (Dusunem Adam 2018). ${ }^{16}$ Impulsivity in bipolar disorder (BD) has been linked to poorer outcome, including a more severe course and suicidality. As a result, there has been a lot of interest in the relationship between impulsivity and BPAD.

Personality makes individuals prone to particular affective states, it may have a role in the etiology of mood disorders(Luke D Smillie 2009. ${ }^{17}$ The interaction between personality and affective disorder is complex with many unresolved issues (TimeaSparding 2017, Kraepelin $1921)^{18,19}$ and other pioneers in psychiatry, hypothesized that deviant personality profile of the average bipolar patient may constitute a premorbid vulnerability for the illness. The five factor model (FFM) is composed of five broad domains 
of dimensional personality traits i.e., neuroticism, extraversion, openness/intellect, agreeableness, and conscientiousness. David Watson, ${ }^{20}$ evidence established that traits are strongly and systematically linked to psychopathology. Highly extraverted individuals are assertive and sociable, rather than quiet and reserved. Agreeable individuals are cooperative and polite, rather than antagonistic and rude. Conscientious individuals are task focused and orderly, rather than distractible and disorganized. Neurotic individuals are prone to experiencing negative emotions, such as anxiety, depression, and irritation, rather than being emotionally resilient. Open individuals have a broad rather than narrow range of interests, are sensitive rather than indifferent to art and beauty, and prefer novelty to routine (Christopher J 2015). ${ }^{21}$ The level of personality functioning had a significant impact on global functioning during the euthymic period of BPAD (2018 Kizilkurt OK1, Gulec MY). ${ }^{22}$ BPAD has a unique personality profile being associated with palpable and significant increases in all three of Neuroticism, Aggressiveness, and Disinhibition (Timea Sparding, 2017). ${ }^{18}$ A specific personality profile during euthymia might be a milder, subclinical manifestation of bipolar disorder and assumed that personality and affective episodes express the same genetic endowment (Akiskal HS, Hirschfeld R1983). ${ }^{23}$ A recent review done by (Hereufuah $2019)^{24}$ found no single dimension of personality qualified as a psychological marker for bipolar disorder and opined that the most promising candidate for marker or endophenotype would seem to be "mpulsivity" as measured by the BIS-II.

There exists a long history of investigation regarding the relationship between personality and affective disorders, specifically, bipolar disorder. A better understanding of this relationship can lead to more accurate diagnoses, improved prognosis and possible improvement of quality of life. For those with the disorder studying personality is also important in bipolar disorder as it can interact with the disease by serving as vulnerability or predisposing factor to a particular disorder. It may be modified, distorted or serves as a direct expression by the presence of the disorder. The current study conducted during euthymic phase to rule out any particular personality trait manifests in the disorder. As it is related to many factors studying impulsivity is important, which the current study focused on this variable and its relation with personality profile during euthymic phase of bipolar disorder compared with healthy controls.

\section{Aims}

1. To study the impulsivity in euthymic bipolar cases

2. To study the personality profile in cases.

3. To compare impulsivity and personality across cases and healthy controls

4. To study the correlation between the variables like impulsivity and personality profiles among cases.

\section{Null hypothesis}

There is no significant difference in impulsivity, quality of life and personality profile between euthymic bipolar subjects and healthy controls.

\section{Materials and Methods}

The study design was cross - sectional and comparative study. The sample size was 50 bipolar disorder euthymic patients and 50 control subjects. Institutional ethical committee approval for study was taken. Convenient sampling technique was used to collect test sample.

\section{Sample description}

Male and Female patients attending review outpatient (op) and discharge committee wards were considered for study. All cases included in test sample were seen by a committee of psychiatrists consisting of one junior postgraduate, checked by one senior postgraduate, one assistant professor and one professor also headed by superintendent. Cases were examined by serial mental status examination over a period of one month. Through this process if any organic mental disorder, dementia, mental retardation if detected were excluded from our study. Current or lifetime diagnosis of a major psychiatric disorder also were excluded by taking history and ICD-10 criteria. Any features suggestive of meeting criteria for personality disorder were referred to clinical psychologist for personality assessment. During this process any diagnosed personality disorder if found were ruled out. All the patients in test sample were pre-morbidly well adjusted. Alcohol abuse not amounting to dependence only were included among test sample because alcohol dependence syndrome would have been confounding factor. Because alcohol dependence syndrome patients may develop alcohol induced mood disorder and psychotic disorder. We wanted to take pure BPAD under remission as our test sample.

\section{Inclusion criteria}

1. Bipolar disorder diagnosis as per 1CD 10.

2. Age between 18 and 60 years.

3. Euthymic at the time of enrolment.

4. Concurrent alcohol and/or other substance abuse with no dependence pattern as per ICD-10

\section{Exclusion criteria}

1. Diagnosed organic mental disorder.

2. Mental retardation.

3. One who diagnosed with personality disorder.

4. Presence of any other serious medical condition

5. Current or lifetime diagnosis of a major psychiatric disorder other than BPAD.

6. Not cooperative and not giving consent.

\section{Procedure}

This study which has a cross-sectional design is conducted after obtaining written informed consent from the patients who were diagnosed Bipolar Disorder according to ICD 10.In this study, 50 euthymic BPAD patients 50 controls 
will be recruited. Euthymia for the purpose of the study was defined as study sample showing scores of Hamilton Depression Rating Scale (HDRS; Hamilton, 196032) $\leq 7$ and Young Mania Rating Scale (YMRS; Young, Biggs, Ziegler, $\&$ Meyer, $\left.1978^{33}\right) \leq 6$, for at least 1 month $\left(\right.$ Brissos $\left.^{34}\right)$ were taken for study. Both test and control sample were administered BIS-11 and Eysenck Personality Inventory (EPI). The healthy attendants of bipolar patients without any psychiatric disorder were taken as controls.

\section{Materials}

1. Written informed consent form in Telugu, English and Urdu.

2. Semi structured intake proforma.

3. ICD10 clinical descriptions and diagnostic guidelines.

4. Young Mania Rating Scale (YMRS)

5. Hamilton Depression Rating Scale (HDRS)

6. Barratt Impulsiveness Scale (BIS-11)

7. The Eysenck Personality Inventory (EPI)

\section{Young Mania Rating Scale (YMRS)}

The scale has 11 items and is based on the patient's subjective report of his or her clinical condition over the previous 48 hours. There are four items that are graded on a 0 to 8 scale while the remaining seven items are graded on a 0 to 4 scale (YMRS; Young, Biggs, Ziegler, \& Meyer, 1978)..$^{25}$

\section{Hamilton Depression Rating Scale (HDRS). ${ }^{26}$}

HDRS form lists 21 items. The scoring was 0-7 = Normal, 8-13 = Mild Depression, 14-18 = Moderate Depression, 19-
$22=$ Severe Depression and $\geq 23=$ Very Severe Depression.

Barratt Impulsiveness Scale (BIS-11) (Patton JH 1995) ${ }^{27}$ It was developed in 1959 to assess impulsivity. It was Selfreport measurement of trait-impulsivity. This test consists of three subscales- 1. Attentional 2. Motor 3. Non planning. The possible scores range from 30 to 120; Total BIS scores generally range from 50 to 60 in healthy persons (Lee SR 2012, ${ }^{28}$ Lewis 2009, ${ }^{29}$ Swann AC $2002^{30}$ )

Eysenck Personality Inventory (EPI) (EYSENCK, H. J., $1968)^{31}$

Measures two pervasive, independent dimensions of personality, Extraversion-Introversion and NeuroticismStability. Each form contains 57 "Yes-No" items with no repetition of items.

\section{Statistical analysis}

Statistical analysis was done using SPSS version 17. Descriptive statistics was used to measure means, percentages and graphs. Analytical statistics like chi square test, independent " $t$ "test were used .p value was set below 0.05 .

\section{Results}

Mean age of test sample was found to be $37.12 \pm 10.804$ SD years, control sample was $38.06 \pm 10.773$ SD years.

Table 1: Socio-demographic variables of test and control sample

\begin{tabular}{|c|c|c|c|c|c|}
\hline \multirow[t]{2}{*}{ Variables } & & \multicolumn{2}{|c|}{ Sample } & \multirow[t]{2}{*}{ Chi Square } & \multirow[t]{2}{*}{ P Value } \\
\hline & & Test & Control & & \\
\hline Sex & Male & 40 & 27 & \multirow[t]{2}{*}{7.644} & \multirow[t]{2}{*}{.006} \\
\hline & Female & 10 & 23 & & \\
\hline Education & Illiterate & 26 & 23 & \multirow{6}{*}{13.469} & \multirow{6}{*}{0.019} \\
\hline & School & 9 & 5 & & \\
\hline & Intermediate & 3 & 9 & & \\
\hline & Undergraduate & 3 & 9 & & \\
\hline & Graduate & 6 & 0 & & \\
\hline & Post Graduate & 3 & 4 & & \\
\hline \multirow{2}{*}{ Marital Status } & Unmarried & 18 & 9 & \multirow{2}{*}{4.110} & \multirow{2}{*}{0.043} \\
\hline & Married & 32 & 41 & & \\
\hline & & & & \multirow{3}{*}{4.336} & \multirow{3}{*}{0.037} \\
\hline Family & No & 37 & 45 & & \\
\hline History & Yes & 13 & 5 & & \\
\hline Total & & $\mathrm{N}=50$ & $\mathrm{~N}=50$ & & \\
\hline
\end{tabular}

Table 2: Showing mean and standard deviation of EPI and BIS-11 of test and control sample

\begin{tabular}{|l|l|c|c|c|c|}
\hline & Sample & N & Mean & Std. Deviation & Std. Error Mean \\
\hline \multirow{2}{*}{ Extrovert Scale } & Test & 50 & 15.44 & 3.157 & .446 \\
\cline { 2 - 7 } & Control & 50 & 13.58 & 2.508 & .355 \\
\hline Neurotic Scale & Test & 50 & 11.04 & 4.682 & .662 \\
\hline
\end{tabular}




\begin{tabular}{|l|l|c|c|c|c|}
\hline & Control & 50 & 10.38 & 4.481 & .634 \\
\hline \multirow{3}{*}{ Lie Scale } & Test & 50 & 3.22 & 1.093 & .155 \\
\cline { 2 - 6 } & Control & 50 & 2.90 & 1.111 & .157 \\
\hline \multirow{3}{*}{ BISTotal } & Test & 50 & 76.26 & 10.089 & 1.427 \\
\cline { 2 - 6 } & Control & 50 & 55.22 & 2.999 & .424 \\
\hline \multirow{3}{*}{ Mottentional } & Test & 50 & 19.94 & 3.755 & .531 \\
\cline { 2 - 6 } & Control & 50 & 15.76 & 1.756 & .248 \\
\hline \multirow{2}{*}{ Non-Planning } & Test & 50 & 26.94 & 5.343 & .756 \\
\cline { 2 - 6 } & Control & 50 & 17.78 & 3.334 & .786 \\
\cline { 2 - 6 } & Test & 50 & 28.86 & 5.559 & .399 \\
\hline
\end{tabular}

Table 3: Showing correlation between EPI and BIS-11 of test sample

\begin{tabular}{|l|l|c|c|c|}
\hline \multicolumn{2}{|c|}{} & \multicolumn{3}{c|}{ t-test for Equality of Means } \\
\hline \multirow{2}{*}{ Extrovert Scale } & & T & Df & Sig. (2-tailed) \\
& Equal variances assumed & 3.262 & 98 & .002 \\
\cline { 2 - 5 } & Equal variances not assumed & 3.262 & 93.231 & .002 \\
\hline \multirow{2}{*}{ Neurotic Scale } & Equal variances assumed & .720 & 98 & .473 \\
\cline { 2 - 5 } & Equal variances not assumed & .720 & 97.812 & .473 \\
\hline \multirow{2}{*}{ BISTotal } & Equal variances assumed & 1.451 & 98 & .150 \\
\cline { 2 - 5 } & Equal variances not assumed & 1.451 & 97.975 & .150 \\
\hline \multirow{2}{*}{ Attentional } & Equal variances assumed & 14.135 & 98 & .000 \\
\cline { 2 - 5 } & Equal variances not assumed & 14.135 & 57.590 & .000 \\
\hline \multirow{2}{*}{ Motor } & Equal variances assumed & 7.130 & 98 & .000 \\
\cline { 2 - 5 } & Equal variances not assumed & 7.130 & 69.459 & .000 \\
\hline \multirow{2}{*}{ Non-Planning } & Equal variances assumed & 10.285 & 98 & .000 \\
\cline { 2 - 5 } & Equal variances not assumed & 10.285 & 82.131 & .000 \\
\cline { 2 - 5 } & Equal variances assumed & 8.143 & 98 & .000 \\
\cline { 2 - 5 } & Equal variances not assumed & 8.143 & 72.720 & .000 \\
\hline
\end{tabular}

Table 4: Showing correlation between EPI and BIS-11 of test sample.

\begin{tabular}{|c|c|c|c|}
\hline \multicolumn{2}{|c|}{ 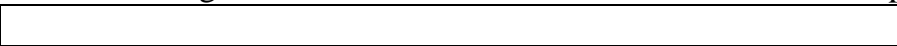 } & Neurotic Scale & Extrovert Scale \\
\hline \multirow[t]{3}{*}{ Neurotic Scale } & Pearson Correlation & 1 & .140 \\
\hline & Sig. (2-tailed) & & .333 \\
\hline & $\mathrm{N}$ & 50 & 50 \\
\hline \multirow[t]{3}{*}{ Extrovert Scale } & Pearson Correlation & .140 & 1 \\
\hline & Sig. (2-tailed) & .333 & \\
\hline & $\mathrm{N}$ & 50 & 50 \\
\hline \multirow[t]{3}{*}{ BISTotal } & Pearson Correlation & .214 & $.335^{*}$ \\
\hline & Sig. (2-tailed) & .136 & .018 \\
\hline & $\mathrm{N}$ & 50 & 50 \\
\hline \multirow[t]{3}{*}{ Attentional } & Pearson Correlation & .268 & .078 \\
\hline & Sig. (2-tailed) & .060 & .590 \\
\hline & $\mathrm{N}$ & 50 & 50 \\
\hline \multirow[t]{3}{*}{ Motor } & Pearson Correlation & .208 & .045 \\
\hline & Sig. (2-tailed) & .147 & .756 \\
\hline & $\mathrm{N}$ & 50 & 50 \\
\hline \multirow[t]{3}{*}{ Non-Planning } & Pearson Correlation & .064 & $.315^{*}$ \\
\hline & Sig. (2-tailed) & .660 & .026 \\
\hline & $\mathrm{N}$ & 50 & 50 \\
\hline
\end{tabular}


Table 1 male and female test and control sample chi square was 7.644 with significant value $p=.006$. The literates and illiterates in test and control sample chi-square was 13.469 with significant value $\mathrm{p}=0.019$. The marital status in test and control sample chi square was 4.110 with significant value $\mathrm{p}=0.043$. With and without family history in test and control chi square was 4.336 with significant value $\mathrm{p}=0.037$.

\section{Independent $\mathbf{t}$ - test between EPI and BIS}

As shown in table 2 independent sample t-test was done between the test sample mean and control for Eysenck personality inventory scale (EPI) and Barrats Impulsivity Scale (BIS).For extroversion scale the difference between test and control sample mean was found to be statistically significant with values $[\mathrm{t}=3.262, \mathrm{p}=.002]$.For neurotic scale the difference between test and control sample mean was not found to be statistically significant with values $[\mathrm{t}=.720$, $\mathrm{p}=.473]$. For Lie scale the difference between test and control sample mean was not found to be statistically significant with values[t=1.451, $\mathrm{p}=.150]$.

\section{BIS score}

BIS total score $[\mathrm{t}=14.135, \mathrm{p}<0.0001]$, attentional subscale $[\mathrm{t}=7.130, \mathrm{p}<0.0001]$, motor subscale $[\mathrm{t}=10.285, \mathrm{p}<0.0001]$ and non-planning subscale $[\mathrm{t}=8.143, \mathrm{p}<0.0001]$ all were found statistically significant.

\section{Correlation between personality profile and BIS}

As shown in table 3 Pearson correlation test was done between neurotic scale and total score BIS its individual subscales among test sample. The neurotic scale has positive correlation with total score of $\operatorname{BIS}(\mathrm{r}=0.214, \mathrm{p}=0.136)$, attentional subscale $(\mathrm{r}=.268, \mathrm{p}=.060)$, Motor subscale $(\mathrm{r}=.208, \mathrm{p}=.147)$ and Non planning sub scale $(\mathrm{r}=.064$, $\mathrm{p}=.660$ ). None of the above findings was found statistically significant. Pearson correlation test was done between extraversion scale and total score BIS among test sample. The extraversion scale has positive correlation with total score of BIS $(r=0.335, p=0.018)$, attentional score $(r=.078$, $\mathrm{p}=.59)$, motor subscale $(\mathrm{r}=.0 .45, \mathrm{p}=.756)$, non-planning subscale $(\mathrm{r}=.315, \mathrm{p}=.026)$. Among the above scores only non-planning impulsivity was found significant.

\section{Discussion}

The aim of this cross-sectional study was to find Impulsivity and personality profile in euthymic bipolar affective disorder patients compared with controls.50 cases were taken for assessment after meeting inclusion criteria along with 50 controls were taken for the study. In the current study for 50 test sample mean age is 37.12 with SD 10.804 . For 50 control sample the mean age value is 38.06 with SD 10.773. Mean age of both test and control is in line with Lauren E Lombardo, $2012^{35}$ Yoon-Seok Kim. ${ }^{36}$ In the above mentioned study sample number of unmarried and married subjects almost equal, which is not in line with our study. Raman Deep Pattanayak $2012^{37}$ an Indian study, sample among test with and without positive family history was in accordance with the current study sample. The results reported for trait impulsiveness assessments with the Barratt Impulsiveness Scale in euthymic bipolar patients are remarkably similar across studies, with higher scores for euthymic bipolar patients than for controls as seen in the below respective studies Ekinci et al., 2011 with $\mathrm{p}<0.001^{38}$ Gilbert et al., 2011b p $<0.01^{39}$ Kathleen Holmes et al., 2009 $\mathrm{p}<0.0001 ;{ }^{40}$ Peluso et al., $2007 \mathrm{p}<0.05 ;{ }^{41}$ Perroud et al., $2011 \mathrm{p}<0.0001,{ }^{42}$ Swann et al., $2001 \mathrm{p}<0.0001,{ }^{43} 2003$ with $\left.\mathrm{p}<0.001,{ }^{44} 2004 \mathrm{p}<0.01\right],{ }^{45} 2009$ with $\mathrm{p}<0.001,{ }^{46} 2010$ with $\mathrm{p}<0.001 .^{47}$ Our study found that all three facets of impulsivity of test sample are increased when compared with control population. BIS total and subscales are statistically significant from control with value of $p<0.0001$ which in accordance with above studies. Our study is also in accordance with recent study by (Mustafa ozen 2019), ${ }^{48}$ who found both inter episode bipolar and unipolar disorder patients had increased impulsivity compared to healthy individuals. Dusunemadam 2018 study $^{16}$ also found increased impulsivity in remission was affecting functionality in bipolar disorder.

There are only few longitudinal studies, one of them is Strawoski SM et al $2010^{49}$ they followed up participants for one year and found increased impulsivity during euthymic phase compared to controls. Kirsten E. Gilbert, $2011^{50}$ study tried to find out impulsivity across the course of bipolar disorder. In the above study non planning impulsivity was not significant which was significant in our study. Lewis et al. $(2009)^{38}$ study examined the relationship of impulsivity and personality characteristics in remitted bipolar disorder patients which is almost equal to our study by using same scales in our study. But they took syndromal, subsyndromal and remitted patients to know whether it is a trait marker. They found no difference in BIS-11 and EPQ scores between remitted patients and healthy subjects. Impulsivity, Neuroticism and psychoticism scores were increased in subsyndromal and syndromal patients and concluded that increased impulsivity may not be a trait feature of bipolar disorder. This study is not in accordance with our study which showed increased impulsivity and extroversion during remission. An increase is seen in both of the two elements of impulsivity, state and trait impulsivity (peluso 2007). ${ }^{41}$ Particular trait impulsivity, which is of a permanent nature, is known to be related with suicide risk, substance use, and non-compliance with medication (Swan 2005, ${ }^{51}$ $2007^{52}$ ) can lead to a chronification of the disease (swan $2005)^{51}$ and it predicts to reach euthymia.

Regarding the personality during remission, neuroticism scores have been found to decrease (Liebowitz et al $1979,{ }^{53}$ Perris $1971,{ }^{54}$ Platman and Plutchik 1970) ${ }^{55}$ and extraversion scores to increase (Perris 1971, Platman and Plutchik, 1970). ${ }^{54,55}$ Both extroversion and psychoticism increase during remission as per study by Okan Ekinci 2013) ${ }^{56}$ In our study mean extraversion scores (SD) showed statistically significant difference between test and controls $(\mathrm{p}=.002)$. Neuroticism score mean (SD) in test and controls didn't find any significant difference $(\mathrm{p}=0.473)$. During euthymic phase, high neuroticism and low extroversion scores predicted a future depression-prone course Barnett $\mathbf{J}$ 
H 2011. ${ }^{57}$ Timiea Sparding $2017^{18}$ did a 2-year follow-up study found Higher neuroticism at baseline predicted future depressive episodes and suicide attempts/violent behaviour, but this association disappeared when adjusting for baseline depressive symptoms as assessed with MADRS. Our study found high extroversion scores during remission compared with controls.

In our study we correlated between neurotic score and BIS to find out association, for test sample. The neurotic scale has positive correlation with total score of BIS, attentional, motor and non-planning sub scale but none of them found statistically significant. The extroversion scale also has positive correlation which found statistically significant with total BIS and non-planning sub scales.

\section{Strengths}

1. Current study utilised strict criteria for remission of bipolar disorder

2. present study analyzed correlation between variables like personality and impulsivity which was not previously studied.

\section{Limitations}

1. Our study is a crossectional study. A longitudinal study design would have studied variables in a better manner.

2. Size of sample is small, hence cannot be generalized.

3. Our study used self rating scales for assessment of impulsivity and QOL.

4. Cases and controls could not be matched for sociodemographic factors like gender, education and marital status. Results have to be interpreted with caution keeping in view of this confounding factors.

\section{Recommendations for Future Research}

Further studies has to focus impulsivity on both during euthymia and the course of illness to delineate state from trait which was lacking in our current study, and also has to focus on increased impulsivity during euthymic phase to find out whether it is a residual symptom or previous mood related activity or vulnerability factor or whether inter episode impulsivity is a risk factor for the disorder or a consequence of multiple episodes (F. Gerard Moeller, M.D. Ernest 2001). Personality profile has to be studied further across the course of the disorder to know specific triats predicts manic and depressive symptoms in bipolar disorder patients (Brian E. Lozano 2001) where limited research is available presently in this area. Understanding specific personality profile in bipolar patients across the course will be helpful to know why some individuals have more frequent relapses, poor drug compliance, more severity of symptoms, chronic course and poor outcome, so that further psychological interventions may be beneficial to address the above issues.

\section{Source of Funding}

None.

\section{Conflict of Interest}

None.

\section{References}

1. Moraes, Paulo Henrique Paiva de. Relationship between neuropsychological and clinical aspects and suicide attempts in euthymic bipolar patients. Psicol Reflex Crit. 2013:(26):160.

2. The ICD 10 Classification of Mental and Behavioural Disorders. Clinical descriptions and diagnostic guidelines.

3. Mathers C, Fat DM, Boerma J. The Global Burden of Disease: 2004 Update. Geneva: World Health Organization; 2008.

4. Weissman MM, Bland RC, Canino GJ, Faravelli C, et al. Cross-national epidemiology of major depression and bipolar disorder. JAMA. 1996;276:293-9.

5. Angst J. The emerging epidemiology of hypomania and bipolar II disorder. J Affect Disord. 1998;50:143-51.

6. Michalak EE, Yatham LN, Wan DDC, BSc, Lam RW. Perceived quality of life in patients with bipolar disorder. Does group psychoeducation have an impact? Can J Psychiatry. 2005(50):95-100.

7. Daruna JH, Barnes PAMcCown WG, Johnson JL, Shure MB. A neurodevelopmental view of impulsivity. The Impulsive Client Theory, Research and Treatment. Washington, DC: American Psychological Association; 1993; pp. 23-37.

8. Barratt ES. Impulsiveness and aggression. In: Monahan J, Steadman HJ, editors. Violence and Mental Disorder: Developments in Risk Assessment. Chicago: University of Chicago Press; 1994. pp. 61-79.

9. Reynolds B, Ortengren A, Richards JB, De Wit H. Dimensions of impulsive behaviour: personality and behavioural measures. Pers Individ Dif. 2006;40:305-15.

10. Moeller FG, Barratt ES, Dougherty DM, Schmitz JM, Swann AC. Psychiatry aspects of impulsivity. Am J Psychiatry. 2001;158:1783-93.

11. Sunohara GA, Malone MA, Rovet J, Humphries T, Roberts W, Taylor MJ. Effect of methylphenidate on attention in children with attention deficit hyperactivity disorder (ADHD): ERP evidence. Neuropsychopharmacol. 1999;21:218-28.

12. Gray JA. A model of the limbic system and basal ganglia: applications to anxiety and schizophrenia, in The Cognitive Neurosciences. 1995, pp 1165-1176.

13. Coccaro EF. Central serotonin and impulsive aggression. $\mathrm{Br} \mathrm{J}$ Psychiatry Suppl. 1989;8:52-62.

14. Linnoila M. Low cerebrospinal fluid 5-hydroxyindoleacetic acid concentration differentiates impulsive from nonimpulsive violent behaviour. Life Sci. 1983;33:2609-14.

15. Jentsch JD, Taylor JR. Impulsivity resulting from frontostriatal dysfunction in drug abuse: implications for the control of behaviour by reward-related stimuli. Psychopharmacol (Berl). 1999; 146:373-90.

16. Dusunen Adam. Relationship of functionality with impulsivity and coping strategies in Bipolar disorder. J Psychiatry Neurol Sci. 2018;31:21-2930.

17. Smillie LD, Bhairo Y, Gray J, Gunasinghe C, Elkin A, McGuffin P, et al. Personality and the bipolar spectrum :normative and classification data for the Eysenck personality questionnaire-revised. Comprehensive Psychiatry. 2009;50:4853.

18. Sparding T, Pålsson E. Personality traits in bipolar disorder and influence on outcome. BMC Psychiatry. 2017;17:159

19. Kraepelin E. Manic depressive insanity and paranoia. J Nerv Ment Dis. 1921;53(4):350.

20. Watson D, Gameza W, Simms LJ. Basic dimensions of temperament and their relation to anxiety and depression: A symptom-based perspective. J Res Personal. 2005;39:46-66.

21. Soto CJ, Anna Kronauer Josephine K. Liang Five-Factor Model of Personality 2015. 
22. Kizilkurt OK, Gulec MY, Giynas FE, Gulec H. Effects of personality functioning on the global functioning of patients with bipolar disorder. Psychiatry Res. 2018;266:309-16.

23. Akiskal HS, Hirschfeld R, Yerevanian BI. The relationship of personality to affective disorders: a critical review. Arch Gen Psychiatry. 1983;40(7):801.

24. Osher Y, Bloch Y. Personality in euthymic bipolar patients as measured by self-report instruments. Harefuah. 2019;158(7):458-62

25. Young RC, Biggs JT, Ziegler VE, Meyer DA. A rating scale for mania: reliability, validity and sensitivity. Br J Psychiatry. 1978;133:429-35.

26. Hamilton M. A rating scale for depression. J Neurol, Neurosurg Psychiatry. 1960;23:56-62.

27. Patton JH, Stanford MS, Barratt ES: Factor structure of the Barratt Impulsiveness Scale. J Clin Psychol. 1995;51:768-74.

28. Lee SR, Lee WH, Park JS, Kim SM, Kim JW, Shim JH. The study on Reliability and Validity of Korean Version of the Barratt Impulsiveness Scale-11-Revised in nonclinical adult subjects. J Korean Neuropsychiatr Assoc. 2012;51:378-86.

29. Lewis M1, Scott J, Frangou S. Impulsivity, personality and bipolar disorder. Eur Psychiatry. 2009;24(7):464-9.

30. Swann AC, Bjork JM, Moeller FG, Dougherty DM. Two models of impulsivity: relationship to personality traits and psychopathology. Biol Psychiatry. 2002;51:988-94.

31. Eysenck HJ, Eysenck SBG. Eysenck Personality Inventory, manual. San Diego: Educational \& Industrial Testing Service, 1968.

32. Ekinci O, Asliekinci, Hastanesi YD, Bolumu P. An investigation of the three Factor model of personality and its relationships with clinical characteristics in major mood disorders. Arch Neuropsychiatry. 2013;50:15-22.

33. Kim B, Lim JH, Kim SY, Joo YH. Comparative study of personality traits in patients with bipolar I and II disorder from the five-factor model perspective. Psychiatry Investig. 2012;9(4):347-53.

34. Brissos S1, Dias VV, Carita AI, Martinez-Aran. A quality of life in bipolar type I disorder and schizophrenia in remission: clinical and neurocognitive correlates. Psychiatry Res. 2008;160(1):55-62

35. Lombardo LE, Bearden CE, Barrett J. Trait impulsivity as an endophenotype for bipolar I disorder. Bipolar Disord. 2012;14(5):565-70.

36. Kim YS, Cha B, Lee D, Sun-MiKim. The relationship between impulsivity and quality of life in euthymic patients with bipolar disorder. Psychiatry Invest. 2013;10(3):246-52.

37. Pattanayak RD1, Sagar R, Mehta M. Neuropsychological performance in euthymic Indian patients with bipolar disorder type I: correlation between quality of life and global functioning. Psychiatry Clin Neurosci. 2012;66(7):553-63.

38. Ekinci O, Albayrak Y, Ekinci AE., Caykoylu A. Relationship of trait impulsivity with clinical presentation in euthymic bipolar disorder patients. Psychiatry Res. 2011;190(2-3):25964.

39. Gilbert, K.E., Kalmar, J.H., Womer, F.Y., Markovich, P.J et al. Impulsivity in adolescent bipolar disorder. Acta Neuropsychiatrica. 2011;23:57-61.

40. Holmes KM, Bearden CE, Barguil M, Fonseca M. Conceptualizing impulsivity and risk taking in bipolar disorder: importance of history of alcohol abuse. Bipolar Disord. 2009;11(1):33-40.

41. Peluso M, Hatch J, Glahn D, Monkul E, Sanches M, Najt P. Trait impulsivity in patients with mood disorders. $J$ Affect Disord. 2007;100(1-3):227-31.

42. Perroud N, Baud P, Mouthon D, Courtet P, Malafosse A. Impulsivity, aggression and suicidal behavior in unipolar and bipolar disorders. J Affective Disord 2011;(134):112-8.
43. Swann AC, Anderson JC, Dougherty DM, Moeller FG. Measurement of inter-episode impulsivity in bipolar disorder. Psychiatry Res. 2001;101(2):195-7.

44. Swann AC, Pazzaglia P, Nicholls A, Dougherty DM, Moeller F. Impulsivity and phase of illness in bipolar disorder. $J$ Affect Disord. 2003;73:105-11.

45. Swann AC, Dougherty DM, Pazzaglia PJ, Pham M, Moeller F. Impulsivity: a link between bipolar disorder and substance abuse. Bipolar Disord. 2004;6:204-12.

46. Swann AC, Lijffijt M, Lane SD, Steinberg JL, Moeller FG: Increased trait-like impulsivity and course of illness in bipolar disorder. Bipolar Disord. 2009;11:280-8.

47. Swann AC, Lijffijt M, Lane SD, Steinberg JL, Moeller FG. Interactions between bipolar disorder and antisocial personality disorder in trait impulsivity and severity of illness. Acta Psychiatrica Scand. 2010;121:453-61.

48. Ozen M, Etil A. Impulsivity differences between bipolar and unipolar depression. Indian J Psychiatry. 2019;61(2):156-60.

49. Strakowski SM, Fleck DE, DelBello MP, Adler CM, Shear PK, Kotwal R, Arndt S:Impulsivity across the course of bipolar disorder. Bipolar Disord. 2010;12:285-97.

50. Gilbert KE, Kalmar JH. Impulsivity in Adolescent Bipolar Disorder. Acta Neuropsychiatr. 2011;23(2):57-61.

51. Swann AC, Dougherty DM, Pazzaglia PJ, Pham M, Steinberg JL, Moeller FG. Increased impulsivity associated with severity of suicide attempt history in patients with bipolar disorder. Am J Psychiatry. 2005;162(9):1680-7.

52. Swann AC1, Moeller FG, Steinberg JL, Schneider L, Barratt ES, Dougherty DM: Manic symptoms and impulsivity during bipolar depressive episodes. Bipolar Disord. 2007;9(3):206-12

53. Liebowitz MR, Stallone F, Dunner DL, Fieve RF. Personality features of patients with primary affective disorder. Acta Psychiatr Scand. 1979;60:214-24.

54. Perris C. Personality patterns in patients with affective disorders. Acta Psychiatr Scand. 1971;221:43-5.

55. Platman SR, Eysenck PR. Personality inventory as a mood test with manic-depressive patients. Psychol Rep. 1970.;947-52.

56. Ekinci O, Asliekinci. An investigation of the three Factor model of personality and its relationships with clinical characteristics in major mood disorders. Arch Neuropsychiatry. 2013;50:15-22.

57. Barnett JH, Huang J, Perlis RH, Young MM. Personality and bipolar disorder: dissecting state and trait associations between mood and personality. Psychol Med. 2011;41(8):1593-604.

58. Moeller FG, Barratt ES. Psychiatric aspects of impulsivity. Am J Psychiatry. 2001;158:1783-93.

59. Brian E. Lozano and Sheri L. Johnson Can personality traits predict increases in manic and depressive symptoms? J Affect Disord. 2001;63(1-3)103-11.

How to cite this article: Sandhya K, Sireesha S, Sudharani. A cross-sectional and comparative study of impulsivity and personality profile in euthymic bipolar affective disorder patients and controls. Telangana $J$ Psychiatry. 2020;6(1):69-75. 